\title{
MEASUREMENT OF THE SENSITIVITY OF THE SMALLEST BLOOD VESSELS IN HUMAN SKIN : RESPONSES TO GRADED MECHANICAL STIMULATION IN NORMAL MEN ${ }^{1}$
}

\author{
By JOSEPH R. DI PALMA, SAMUEL R. M. REYNOLDS, AND FRANCES I. FOSTER \\ (Department of Physiology, Long Island College of Medicine, Brooklyn, New York)
}

(Received for publication February 6, 1941)

The physiological responses of the smallest blood vessels in human skin to mechanical and chemical stimuli have been the subject of numerous studies and several important monographs (1, 2,3 , and others). The qualitative aspects of the white and red reactions of the triple response have been well-defined and their localization to the smallest vessels has been established. Despite the extent of, and widespread interest in this subject, no attempt has been made until now to put these on a simple quantitative basis. Such experiments should enable an observer to measure the sensitivity of the skin capillaries in a subject from day to day, and to compare such data among a group of individuals. The present report offers one of two such methods which we have developed.

The procedure usually employed experimentally to elicit the several components of the triple response are mechanical pressure and local infiltration (by pricking or iontophoresis) of vasodilator or vasoconstrictor drugs. The chemical methods have been used in a quasi-quantitative manner (4, $5,6)$ but these tests depend upon a number of factors which may only indirectly involve the sensitivity of the capillaries. Plethysmographic studies and measurements of skin temperature likewise fail to reflect the irritability of the smallest vessels $(7,8)$. The response of these vessels to graded mechanical stimulation offers, on the contrary, a direct approach to this problem. The technic described below depends upon this principle. Its application rests upon control of two qualities of a stimulus, namely, intensity and duration. Thus, if a true measure of the excitability of the vessels were obtained, a typical strength-duration curve like that found in determining the threshold of

1 Supported by grants from the Josiah Macy, Jr. Foundation and the Committee on Endocrinology, National Research Council. The authors are indebted to Doctor George B. Ray for criticism and suggestions throughout the course of this work, and to Doctor Hallowell A. Davis for criticizing the manuscript. excitability in nerve or muscle would result. The apparatus described below yields such data simply and quickly.

\section{METHOD AND PROCEDURES}

Apparatus. This consists of a machine which varies two factors in a critical manner. The intensity factor is varied manually by changing the weights on a skin stroker. The duration factor is varied by having a device which will move this loaded skin stroker over the forearm at a suitable range of speeds. The duration of the stimulus over any portion of the skin may then be determined by calculation from the rate. In practice, a range of stimulus-durations of 12 to 14 seconds per centimeter to 0.03 seconds per centimeter was found to be necessary. Different speeds of the piston were obtained by controlling the outflow of compressed air in front of a piston on which a constant pressure is exerted. By glancing at Figure 1, it will be seen that moving the carriage toward the reader would move the piston into the cylinder in the opposite direction, thus compressing the column of air in the cylinder. By adjusting the airescape valve at a previously determined position, the piston can be made to move at a given rate down the cylinder provided the tension exerted by the rubber motor remains nearly constant.

The technical details are simple. An ordinary tire pump provides the piston and cylinder. A section nine inches in length is cut off, leaving a blind cylinder with an air outlet. The rod which is attached to the piston is cut off and a length of number 22 gauge piano wire is connected to both sides of the piston. The cable is led off on the compressing side through the end-plate of the cylinder (drilled so as to provide an air seal). Both ends of the cable are looped over ball bearing pulleys and attached to a small turnbuckle on the carriage. The escape valve is a vital part of the machine and must be mechanically perfect. It must permit fine gradations in air-escape, since slight changes in this respect cause marked variations in the speed of piston travel. A valve consisting of two flat discs of number 18 gauge copper one and one-half inches in diameter and ground perfectly flat on one side was found suitable. In one disc, a hole five-thirty-seconds of an inch in diameter is drilled onehalf inch from the center; in the other, a slit threeeighths of an inch long is cut, placed one-half inch from the center, and tapered from one-eighth of an inch to a very fine point. When the ground surfaces of the discs are applied together it will be seen that as one disc is 

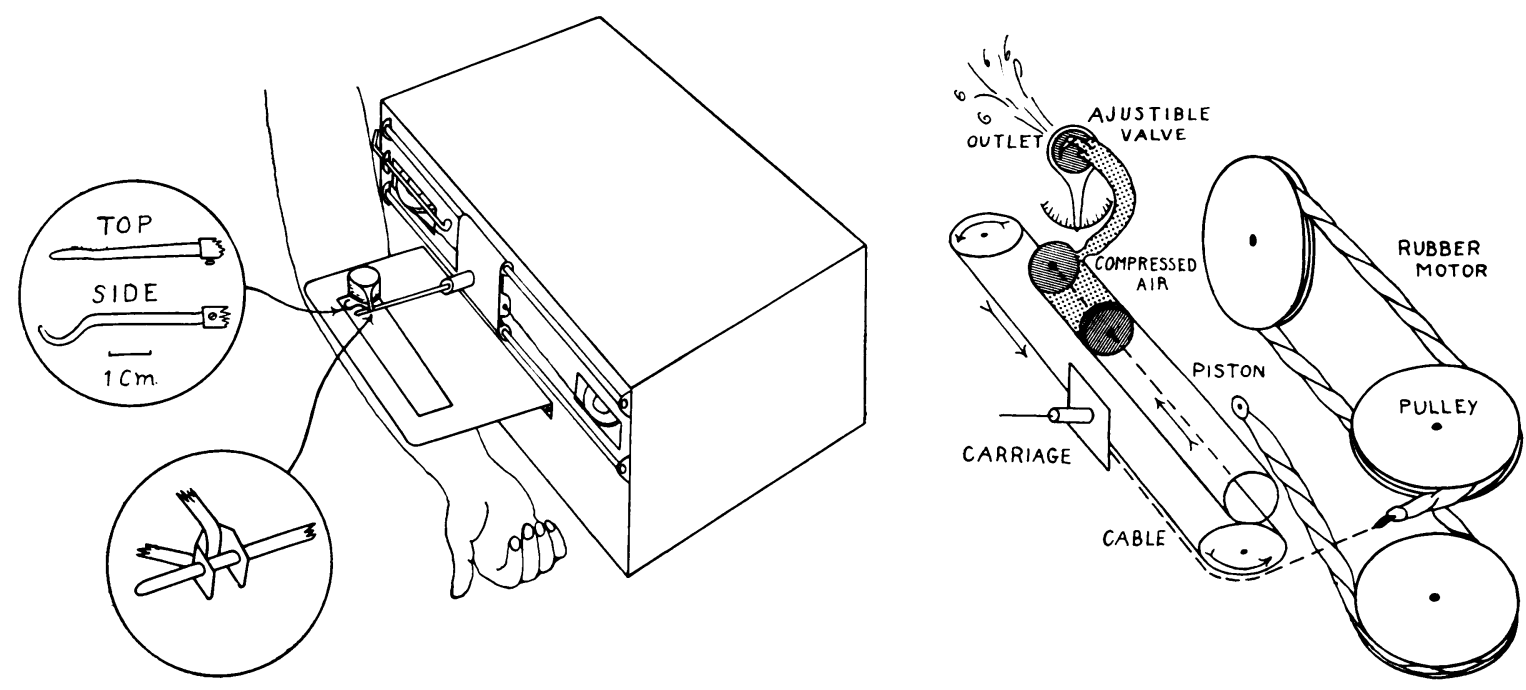

Fig. 1. Dingram of Apparates for Applying Graded Mechanical Stmmlation to Humax Skin

Gradations in weight are obtained by employing selected weights in the carriage of the stroker; in speed, by adjusting the valve which controls the rate of escape of compressed air from the pump. See text for details.

rotated and the other held stationary, the tapering slit is gradually superimposed upon the circular orifice. An airtight connection is made between the circular orifice and the cylinder; a suitable handle is attached to the other disc, and a scale with one degree gradation is constructed. The discs are held together firmly by a spiral spring which runs over a central pivot. By means of brass tubing soldered to each end, the carriage of steel plate rides on tracks of two steel drill rods. A brass bushing holds the rod of the skin stroker. The carriage must run smoothly. An extra slip of cable is connected to the rubber motor, as illustrated. Rubber was used to provide a strong, even pull over a four-inch distance. When fifteen feet of one-fourth of an inch of flat rubber are looped over the four-inch pulleys in ten strands, as shown, this requirement is adequately filled. The skin stroker is a chromium plated brass rod five-thirty-seconds of an inch in diameter and shaped so as to provide a smooth stroking surface to the skin. The end is bent into an arc of 0.5 centimeter and tapered to a diameter of 2.5 millimeters. It should be carefully polished to eliminate all burrs. Such a stroker loaded with five hundred grams covers eighteen square millimeters $(3 \times 6)$ in area on the skin of the forearm. The loading pan is merely a wire basket, as shown in the diagram. In our apparatus it exerts a force of twenty-five grams. The whole apparatus is mounted in a box. A heavy sheet of metal with a rectangular cut-out four inches long and one and onehalf inches wide is mounted below the stroker as an arm guard. It is covered underneath with velvet to avert cold reactions on the skin. The guard also serves to provide a surface on which the stroker runs before touching the skin; during this time, acceleration is completed at all speeds.

In calibrating the machine, a strip of thin metal ex- actly one centimeter wide is attached to the carriage so that it stands upright. The machine is now interposed between a light source and an optical kymograph so that when the carriage moves the thin strip cuts a light beam for an interval of time dependent on its speed of travel. An ordinary electrocardiograph timer of 0.04 second per centimeter is also inserted on the record. The record thus obtained will show a black line with various segments cut out to represent different rates of speed. These rates may be calculated as duration of stimulus per centimeter and conveniently transposed to the scale on the pointer.

Proccdure in an cxperiment. The subject is seated comfortably with a bared arm which is supported on a rubber wedge in place under the platform of the apparatus, as shown in Figure 1. In practice, it is found convenient to have the subject in such a position that the stroker runs up the forearm instead of down, as shown in the diagram. The operator is then seated in position to adjust the valve weights and to reset the stroker. The observations are made under bright lights (two 100-watt bulbs, one blue and one yellow) in reflectors placed at a distance of about thirty inches from the apparatus. They are focused somewhat to one side in order that the full heat from the bulbs does not fall on the arm. The effect of local changes in temperature on the responses under observation will be discussed below. As a matter of record, notation is made of the skin temperature (number 30 gauge wire thermocouple and an L \& N skin potentiometer), dry bulb, wet bulb, humidity, and barometric pressure.

For a determination, the stroker is released to move at any desired speed along a line two to four inches in length. The arm is then held toward the light and the changes in skin color are observed along the line of the stroke. These may vary in the following ways: With 
relatively little weight, an area of pallor (constriction of the skin capillaries (2)), may be seen to develop in the course of 35 to 40 seconds. This fades away in some 2 to 5 minutes. When the pressure is heavier, a bright red line (capillary vasodilatation (2)), of even color and with sharp edges, surrounded by a broad pale area of vasoconstriction with sharply defined edges, is seen along the line of the stroke. Beyond this an irregularly defined flare may be present. Between these two responses is a third one which we have found convenient and easy to employ as the threshold response in measuring the sensitivity of the vascular reactions; it consists of the area of pallor seen in the two responses above plus a faint, mottled or incomplete red line along the line of the stroke. In judging this response, it is essential that a red tint, which acquires a color characteristic of oxygenated blood, be distinguished along the line, and that mere indentation of the skin is not mistaken for the threshold response. Little practice is necessary for this. Examples of the three responses are shown in Figure 2. They have been taken from a model of the forearm on which the tache reactions have been depicted by an artist.

For each successive stimulus-duration the threshold is re-determined, largely by trial and error, using various weights. A little experience shortens the time required for these determinations. After each trial, a new area of the arm is placed under the stroker plate and a reading made. Extensive trials have shown that the inner aspect of either forearm may be used interchangeably in making the points of the strength-duration curves. It is not necessary to clip or shave the hair from the arm; in fact, it is believed that this makes some skins less susceptible to the stimulus of the stroking.

\section{RESULTS}

The strength-duration curve. An example of one of the strength-duration curves, determined in the above manner, is shown in Figure 3. In this, each point, indicated by a dot, is the threshold response. The shaded area indicates, at the top, the curve of appearance of the full maximal response (solid red line) ; at the bottom, the curve of maximal capillary vasoconstriction without the red line. ${ }^{2}$

The position of this curve on the same subject throughout the month of September, 1940, is shown in Figure 4. The similar contours and the fair agreement of the several curves may be seen by noting the relative positions of the various symbols for the separate curves. These curves, it may be mentioned, apparently were not affected in their relation to each other by room temperature (wet or dry bulb), skin temperature, humidity or barometric pressure.

Thus far, curves similar to these (sixteen of which are shown in Figure 5) have been obtained

2 The third point on the curve followed immediately after a period of increased activity, as the subject was called from the room. By the time the next point (second from the left) was determined, recovery had occurred.

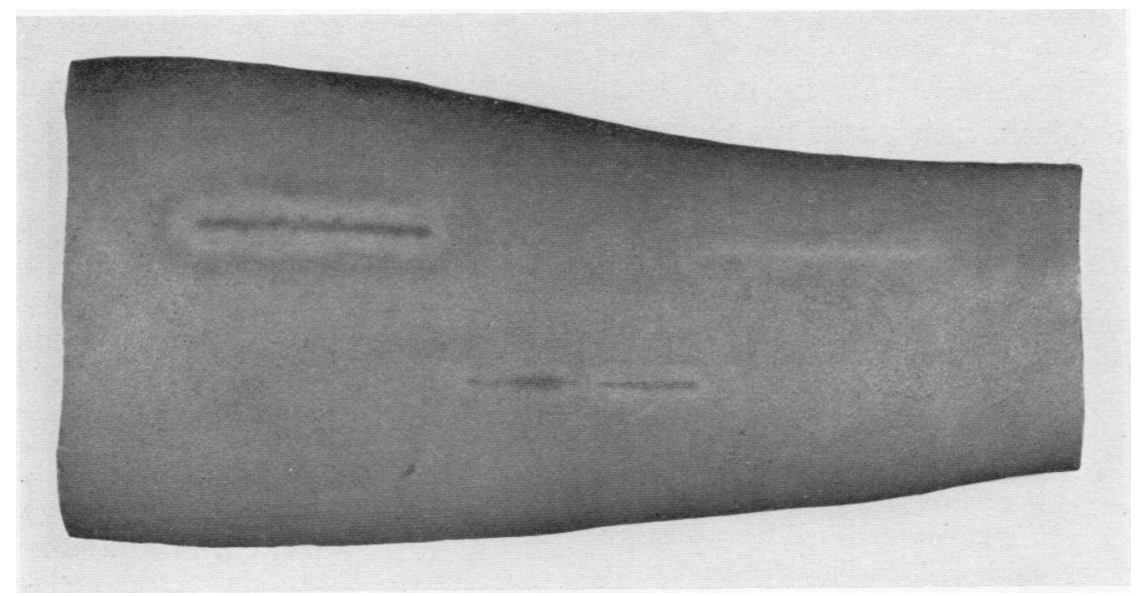

Fig. 2. Photograph, Made from Model of an Arit, Showing the Threshold Response, Sub-Threshold Response, and Super-Threshold Response

The threshold response is represented by a broken, uneven red line of vasodilatation surrounded by a definite but limited pale area of vasoconstriction, the sub-threshold response by a pale area of vasoconstriction only, and the super-threshold response by a strong, continuous red line of vasodilatation, surrounded by a strong, wide area of vasoconstriction; beyond this, as shown here, there may be a red, reflex arteriolar flare. 


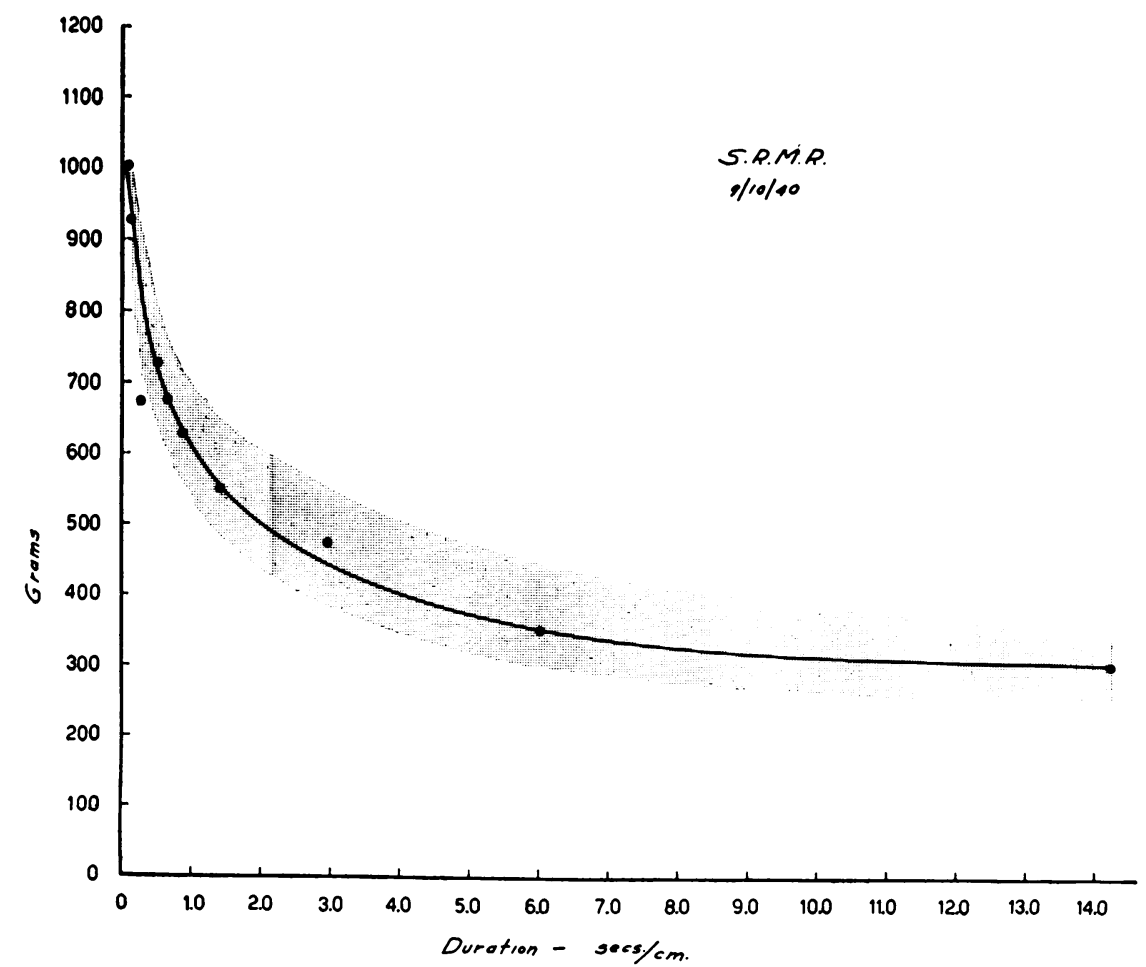

Fig. 3. A Characteristic Time-Intensity Curve of the Threshold Response

The dots indicate actual determinations of the response. The shaded area signifies, at the top, the level at which the super-threshold response is obtained; below, the level at which the sub-threshold (constriction only) is strongest, without a trace of the red. Vasoconstriction may actually be detected faintly down to 20 to 50 grams at any of these speeds. The third point from the left was made immediately after the subject returned to the room, after being called away.

on thirty-eight normal men. ${ }^{3}$ Where more than one curve was obtained, each represents the aver-

3 The choice of males was made by random sampling, and medical students from the first to the fourth years were selected as subjects. None was known to be abnormal or unhealthy in any way. In addition, members of the teaching and technical staff served as subjects. Thirty-five were in the third decade of life and three in the fourth decade. Additional data were obtained on half as many more subjects, but these are not included in Table I since the curves are incomplete. (The data were obtained at a time when it was believed that another method of treatment, which utilized only the region of the inflection of the curve, was possible.) Insofar as they go, these data compare with the more complete curves reported here. It was impossible to obtain curves on only two subjects in the entire group. One of these, a red-headed subject who has never tanned, gave atypical responses throughout the range of stimulus-durations. These were characterized by unusually intense and large areas of erythema along the line of the stroke, without the surrounding area of pallor. The second atypical sub- age of all the curves for any individual. Attention may be called to several features of this group of curves. First, the point of inflection on most curves was obtained at a stimulus-duration of 1 to 2 seconds per centimeter, ten of these requiring between three to four hundred grams to induce the threshold response. The remaining six curves, each of which was typical for the individual from whom it was obtained, showed somewhat different thresholds at the point of inflection. To what this may be attributed, we are unable to say at the present time. Second, with the exception of two curves, the weights necessary for threshold responses at the fastest speed was between five hundred and twenty and eight hundred grams. In the

ject was periodically catatonic. His responses did not appear for from 2 to 5 minutes and they persisted for about half an hour. This is in contrast to the threshold responses in normal subjects which are usually maximal within 40 to 60 seconds and subside within several minutes. 
other two subjects, it was one kilogram. Finally, considerable spread was observed in the weights necessary for threshold responses at the slower speeds. Perhaps this may be ascribed partly to variations in skin thickness or water-content which the heavier weights would circumvent at higher speeds. But its true cause is not known.

Proof of the threshold nature of the strengthduration curve. The response which we have adopted as "threshold" is complex, consisting of an area of vasodilatation against a background of vasoconstriction. Doubt naturally arises, therefore, concerning the significance of the higher stimulus-intensities (weights) required at the faster speeds. May not the increased weight be required to elicit more injury in order to produce, in turn, more vasodilating substance to overcome a stronger vasoconstriction? Alternatively, is the capillary constriction of equal intensity throughout the range of the strength-duration curve, and, hence, is the red line of vasodilatation the result of an equal intensity of chemical inhibition throughout? The question is answered in favor of the latter possibility by the following experiments.

The thresholds were determined at four different speeds. They were then repeated at suitable intervals upon an arm in which various degrees of partial venous occlusion were maintained by a sphygmomanometer cuff applied immediately $b e$ fore laying down the stroke. Two such levels of occlusion were determined, one of which just served to prevent the halo of vasoconstriction along the line of the stroke, the other to permit, in diminished intensity and form, the halo of vasoconstriction. The purpose of this procedure was to show that, if the constriction were more forceful at the higher stimulus-intensities, then higher venous occlusion pressure would be necessary to prevent vasoconstriction than at the lower stimulus-intensities.

The result of one such experiment is shown in Figure 6. It will be seen that, regardless of the

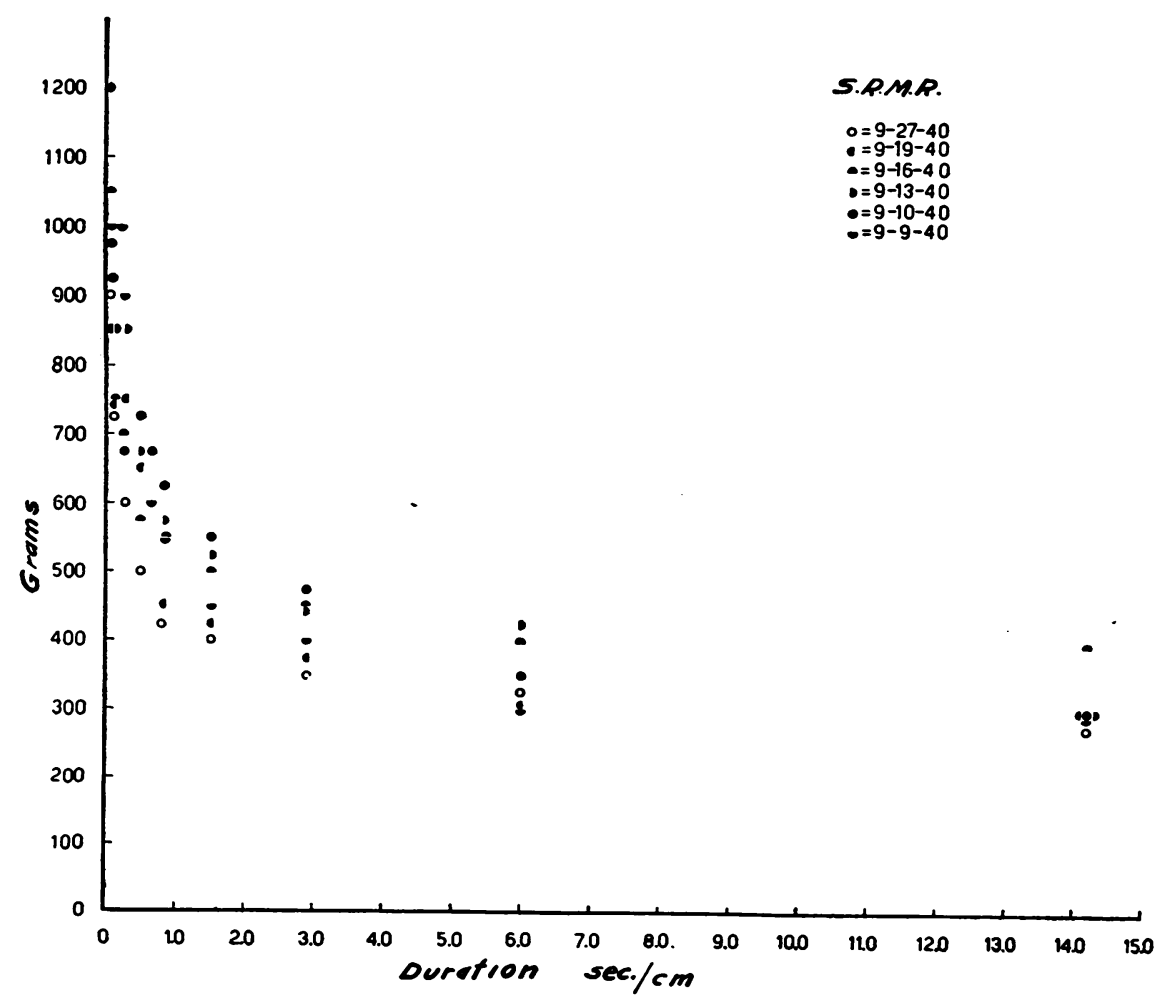

Fig. 4. Time-Intensity Curves Obtained from One Subject During the Month of SEPTEMBer, 1940

There is variation, but this is in the intensity parameter of the several curves, as may be seen by noting the position of any curve by means of the symbols. 


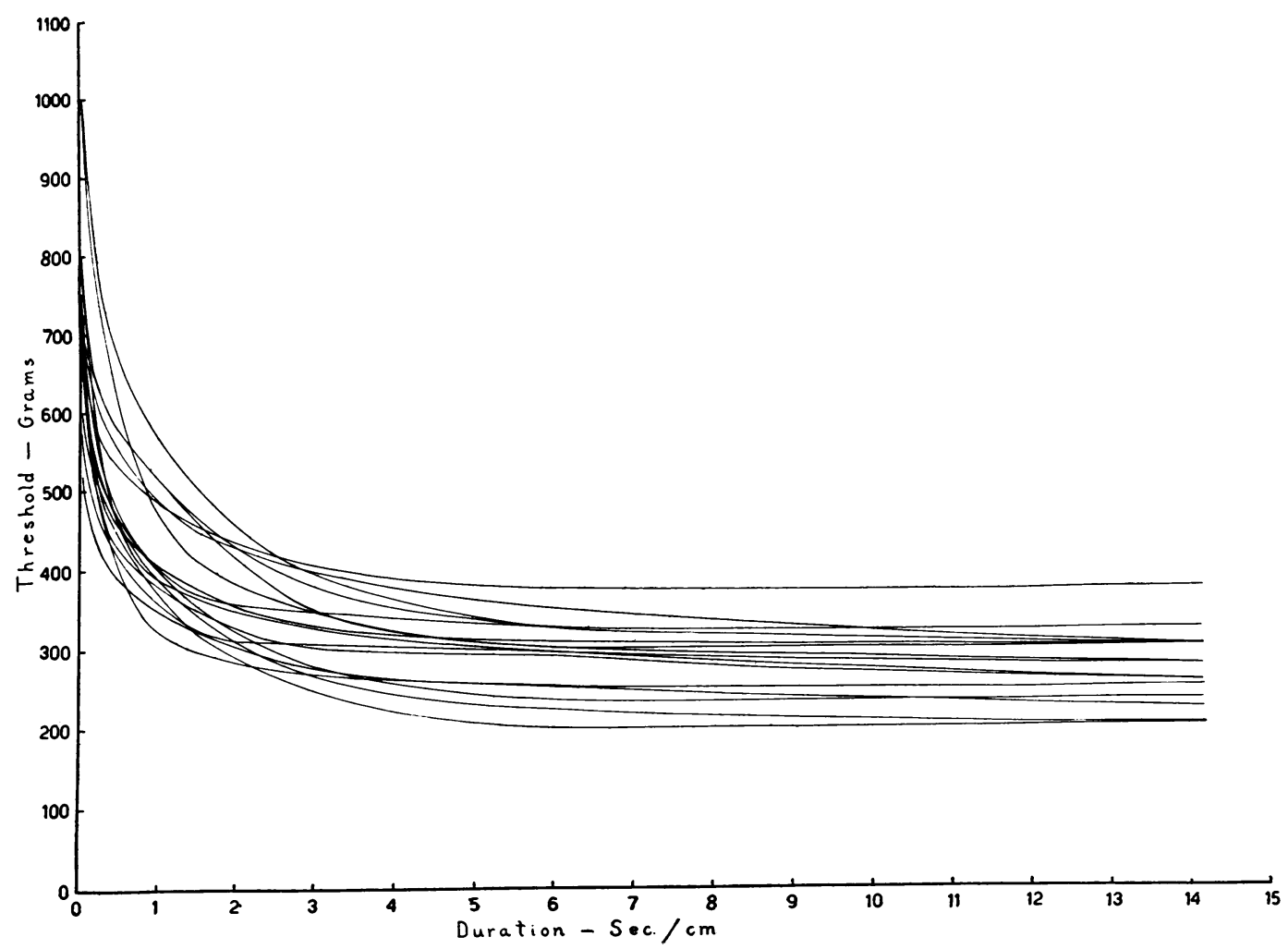

Fig. 5. Single Time-Intexsity Curves Obtained on Sixteex Different, Presumably Normal, Human Males

weights used, fifty millimeters of mercury prevented constriction, whereas forty millimeters of mercury permitted the development of discernible vasoconstriction. In either case, release of the venous circulation soon afterwards regularly permitted development of the response to nearly full intensity, thus showing that fatigue resulting from inadequate circulation had not occurred. Consequently, the conclusion follows that throughout the strength-duration curve described above, we are dealing with responses of about uniform intensity, and the curve is characteristic of the threshold for excitation of the capillary blood vessels to graded mechanical stimulation applied at appropriate rates.

Mention should be made of the fact that we have confirmed the observation of Lewis that, if the stimulus be strong enough, the white and red reactions will develop, even though the venous occlusion pressure approaches a diastolic level.

Effect of complete venous stasis. In view of the fact that responses may be obtained by ade- quate stimulation with partial or complete venous occlusion, it was deemed advisable to investigate quantitatively the effect of stasis on the threshold of response. With complete stasis the circulatory conditions differ markedly from those in partial occlusion. In the latter, the blood flow is momentarily impeded and then continues at a higher pressure level (2), whereas in the former, the capillary blood pressure is materially lowered when arterial inflow is rapidly cut off by pressure.

The effect of circulatory stasis upon the excitability of the smallest vessels in the skin is shown in Figure 7. In this, as in other similar experiments, threshold stimuli were determined at three different speeds following periods of stasis lasting from 1 to 6 minutes. It is clear that circulatory arrest for these periods of time does not abolish the contractility of the smallest blood vessels (confirming Lewis) but it does raise appreciably and progressively their threshold for excitation. The effect is more pronounced when the stimulus is applied quickly. 
To determine why circulatory arrest raises the threshold of the white and red reactions, a further investigation was necessary in order to distinguish between the effects of anoxia and of the action of metabolites and vasodilating substances which are known to accumulate in tissues in which the circulation is arrested.

Effect of anoxemia on the threshold. In this experiment, the subject rebreathed into and out of a closed tank filled with room air. The threshold of the skin response was measured, for one speed only, at intervals during the experiment. Expired air passed through soda lime to remove carbon dioxide. By means of suitable procedures, the oxygen in the expired air was estimated from time to time, and records of systolic pressure, diastolic pressure, heart rate, respiratory rate, and tidal air were made. From the latter, the minute volume of air respired was estimated.

The effects of diminishing oxygen tension in the inspired air are shown in Figure 8a. It will be seen that within 10 minutes, when the oxygen was reduced to about 17 to 18 per cent, a perceptible elevation of the threshold of blood vessel reactivity occurred. There was little effect on blood pressure, heart rate or respiratory rate and depth at this time. As the oxygen in inspired air reached a level of 13 to 14 per cent, however, changes in all the above were recorded, particularly with regard to heart rate and respiratory rate. At about this time, a very abrupt increase in the threshold of the blood vessel reactivity occurred. Anoxemia without stasis, therefore, lowers the sensitivity of the smallest blood vessels in the skin and this is observed before important systemic circulatory and respiratory changes take place.

Effect of hypercapnia on the threshold. The effect of increased carbon dioxide in the expired air presented an interesting contrast to the effect of anoxemia. In Figure $8 \mathrm{~b}$, it will be seen that a marked decrease occurred in the threshold of reactivity of the capillary blood vessels and, as in

\section{EFFECT OF PARTIAL VENOUS OCCLUSION ON \\ CAPILLARY CONSTRICTION}

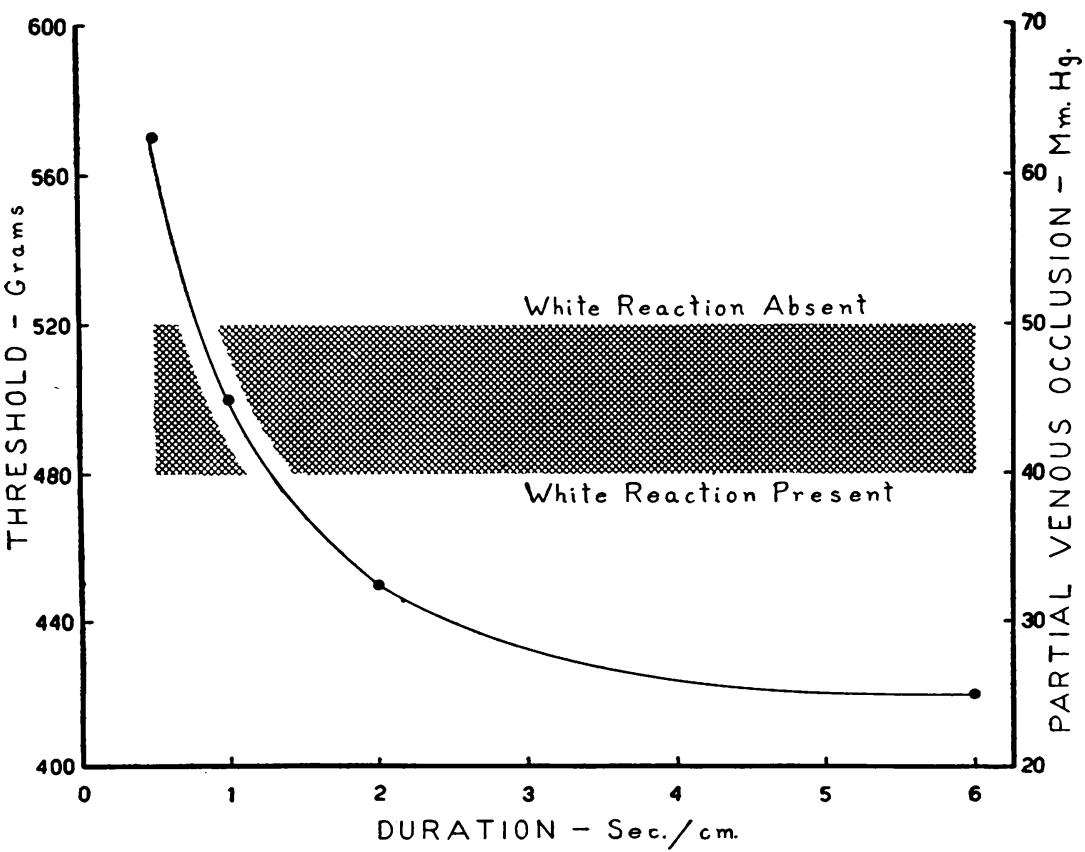

Fig. 6. Proof That the Time-Intensity Cluves of Blood Vessel Response to Graded Mechanical Stimllation Are of Uniform, Threshold Intensity, and Do Not Vary with the Weights, or Speeds Used

Irrespective of the point on the curve, $50 \mathrm{~mm}$. partial venous occlusion pressure, applied just prior to laying down of the stroke, prevented the zone of vasoconstriction, whereas $40 \mathrm{~mm}$. permitted it. 


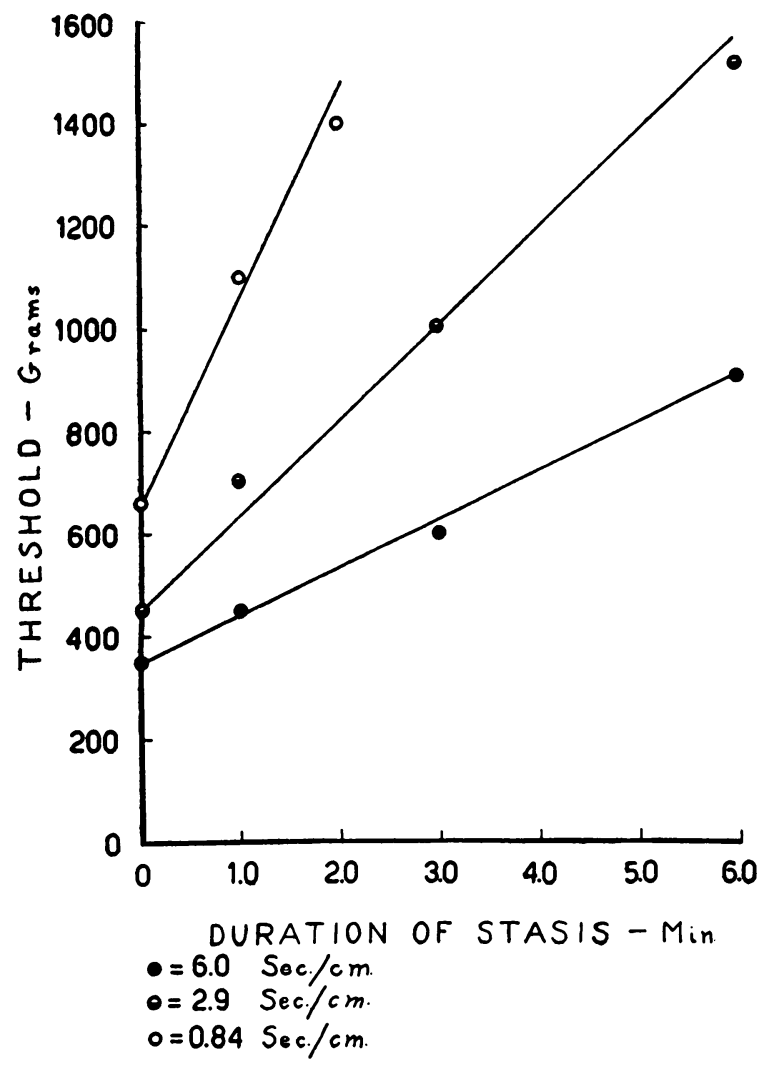

Fig. 7. Effect of Complete Circllatory Stasis on the Threshold Response

At each of three different speeds, the weight necessary for the threshold response increased with increasing duration of stasis.

the anoxemia experiment, this change in threshold was well-marked before important changes in heart rate, blood pressure or respiratory activity took place. Accordingly, these results attest a remarkable sensitivity of the capillary blood vessels to small changes in the gas-content of the blood.

Effect of local temperature changes on the thrcshold. The effect of increase in the local skin temperature on the end-point of the reaction (i.e., the equilibrium point, not the rate) was studied to see if it would be necessary to control rigidly the room temperature during a series of determinations. The result is shown in Figure 9. The tissues were warmed gradually and held at any desired temperature for several minutes. When this was uniform (within 0.3 degrees Fahrenheit) along the line the stroker would take, the threshold was determined. It will be seen from the figure that the change was not very great, even though the range of temperatures extended from 90 to 104 degrees Fahrenheit. This involved, in fact, a change in threshold of about 2 per cent per degree Fahrenheit. Inasmuch as the threshold determination is only read to within about \pm 20 grams (i.e., about 5 to 10 per cent) it may readily be seen that minor changes in room temperature will not seriously affect the shape or position of the strengthduration curve. New experiments, taking into account the rate at which the threshold equilibrium is attained at each temperature, will be required in order to establish, by the Arrhenius (9) equation, the chemical or physical nature of the effect of temperature on the reactivity of the blood vessels to mechanical stimulation.

\section{DISCLSSION}

Criteria for cvaluating excitability of the smallest blood vessels. The results summarized above raise an important question, namely, in what manner may the individual strength-duration curves be employed to indicate relative degrees of bloodvessel excitability in a given person from day to day, or between different subjects? Examination of the curves in Figure 5 demonstrates the impracticability of using a simple measure like a chronaxie value, inasmuch as some curves with a high intensity parameter have a very short-time parameter and vice versa, while some curves cross others at one or two points. Davis and Forbes (10) have reviewed the limitations of chronaxie values. By replotting the data, however, it is evident that each of these curves is characteristic of the strength-duration curves which are obtained in the responses of other types of tissue (e.g., smooth and striated muscle, nerve) to electrical stimulation $(10,11)$. This is demonstrated by plotting the data of the strength-duration curve on double logarithm paper. When this is done, as in Figure 10 , it is found that each curve falls along a straight line. This occurs when the duration of the stimulus is between 0.25 to 2,3 or more seconds per centimeter. This was true for stimulus-durations of about one second per centimeter in two curves only. The slopes of these and other similar curves (Table I) range from 0.19 to 0.55 , with an average of 0.35 . This is less than the range of 0.5 to 1.0 second per centimeter which is found for a variety of tissues in response to electrical stimulation (10). 

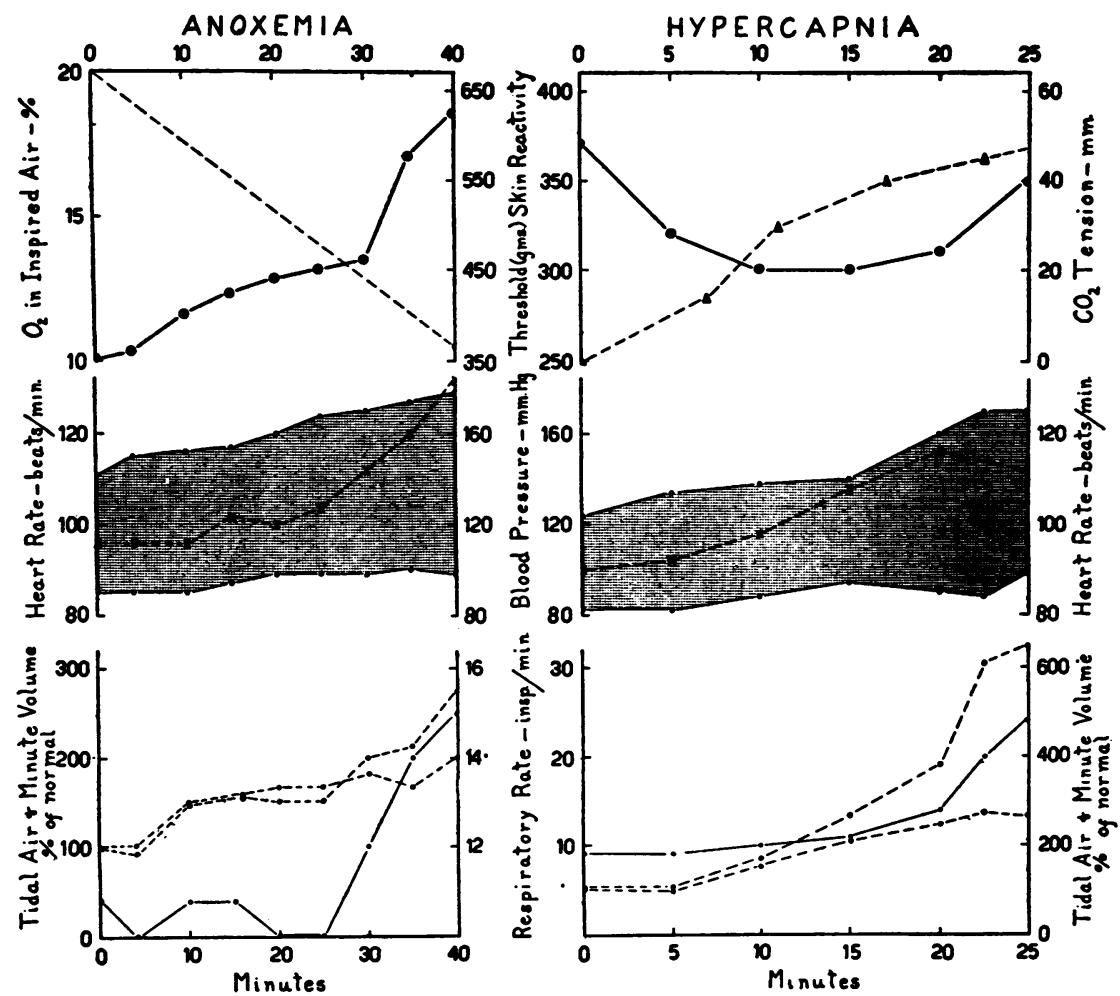

Fig. 8. The Effect of Anoxemia (a) and of Hypercapnia (B) on the Threshold Response (Constant Speed, Variable Weights)

Heavy dots, threshold ; crosses, heart rate; stippled areas, pulse pressure lying between systolic and diastolic pressures. Bottom, continuous line, respiratory rate; circles, minute volume index $(\%)$; dots, tidal air $(\%)$. These data show that changes in the threshold of blood vessel reactivity occur, increasing in anoxemia, decreasing with hypercapnia; in each, the change is detectable before important changes in circulatory or respiratory activities occur.

The selection of an adequate "index of excitability" raises many imposing problems, and no entirely suitable or universally recognized method is available. Davis and Forbes (10) point out that chronaxie is an expression of excitability in terms of the time factor alone, and that this is entirely empirical. They suggest that the "index of excitability" of Lassalle (12) is more adequate since it embraces the intensity factor as well. Therefore, it involves measurement of excitability in terms of energy, and this would seem to offer a better basis for comparison of the relative excitabilities of different strength-duration curves for a single tissue when these are obtained under identical conditions (10). The Lassalle factor is expressed as the index of excitability which is proportional to the reciprocal of the product of the rheobase squared and chronaxie

$$
\text { (i.e., } \left.\mathrm{E}=\frac{1}{\text { rheobase }^{2} \times \text { chronaxie }}\right) \text {. }
$$

This coefficient is calculated and given in Table IA for each of the curves thus far obtained to date on the skins of thirty-eight normal human males. ${ }^{3}$ It will be seen that the most excitable blood vessels $\left(1.6 \times 10^{-4}\right)$ are twenty times as sensitive as the least excitable blood vessels $\left(0.08 \times 10^{-4}\right)$ and that the mean is $0.53 \pm 0.49$. The standard error of the mean is \pm 0.079 . Comparable data for two or more curves on a single individual at intervals of a week to several months are given in Table IB. Here, too, it will be seen that some variation in excitability is found, although the range for any subject is far less than that for the group as a whole. 


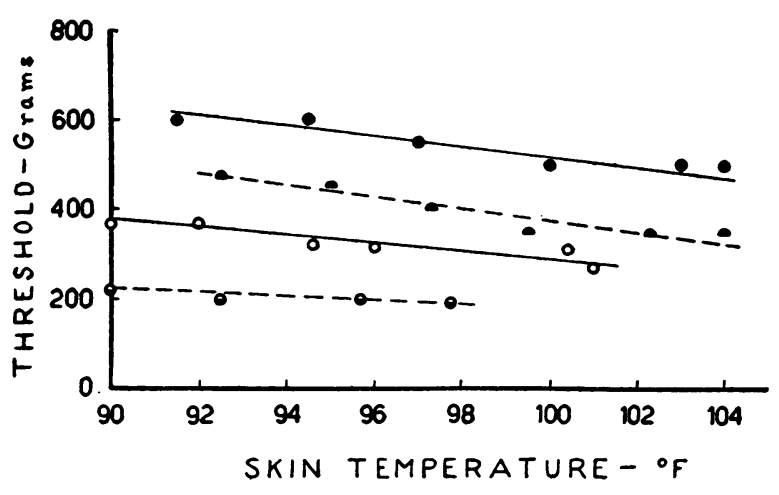

Fig. 9. Effect of InCreasing Surface Temperature Along the Line of Stroke on the Threshold ReSPONSE

Each of these indicates a shift in threshold of about 2 per cent per degree F. Since the response is read, usually, to about \pm 10 per cent, small changes in temperature are relatively unimportant.

In view of the physiological factors which may modify the threshold of excitability in the blood vessels (a few of which are noted in this paper) it is not strange that this variation is found in single individuals and between different individuals.

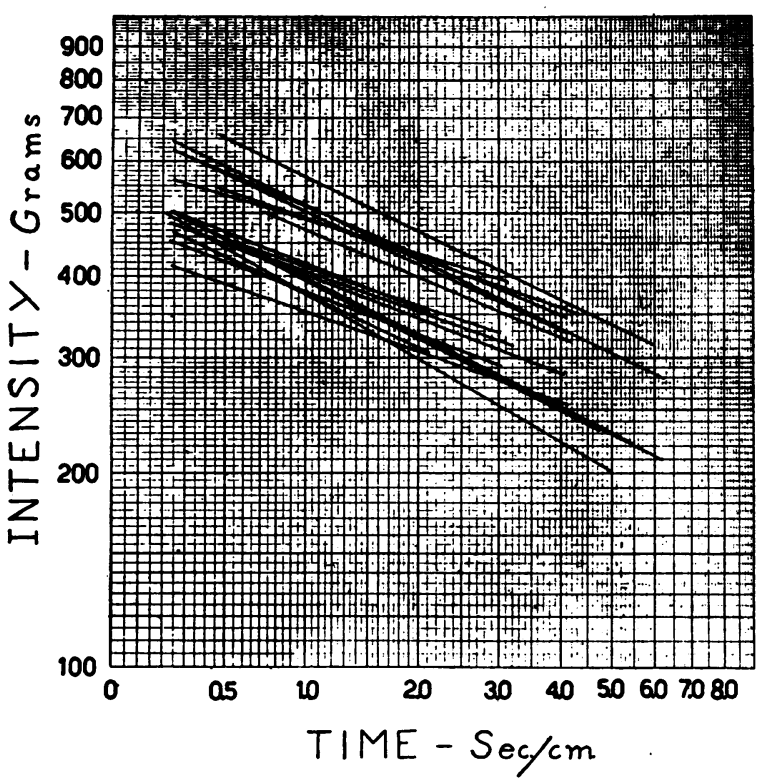

Fig. 10. The Time-Intensity Curves of Figure 5 Plotted on Double Coordinate Logarith m Paper

The line is straight. At the right of each of the curves shown here the change in slope to the rheobase (omitted here for clarity) commences. Such curves are typical of the curves of electrical excitation of a number of tissues. The average slope here (see Table I) is 0.35 .
TABLE I

Summary of the characteristics of the curves of threshold skin vascular reactions to graded mechanical stimulation in thirty-eight normal male subjects

The coefficient of excitability is calculated according to the formula of Lassalle (12).

\begin{tabular}{|c|c|c|c|}
\hline $\begin{array}{c}\text { Slope } \\
\text { log-log } \\
\text { coordinates }\end{array}$ & Rheobase & Chronaxie & $\begin{array}{l}\text { Coefficient of excitability: } \\
\mathrm{E}=\left(\frac{1}{\text { rheobase } \times \text { chronaxie }}\right)\end{array}$ \\
\hline \multicolumn{4}{|c|}{ A. DATA OBTAINED FROM DIFFRRENT BUBJECTS } \\
\hline & grams & $\begin{array}{l}\text { seconds per } \\
\text { centimeter }\end{array}$ & \\
\hline $\begin{array}{l}0.45 \\
0.26 \\
0.50 \\
0.31 \\
0.40 \\
0.37 \\
0.42 \\
0.50 \\
0.55 \\
0.44 \\
0.45 \\
0.50 \\
0.29 \\
0.28 \\
.33 \\
0.38 \\
0.25 \\
0.40 \\
0.50 \\
0.47 \\
0.38 \\
0.51 \\
0.28 \\
0.38 \\
0.43 \\
0.45 \\
0.23 \\
0.38 \\
0.35 \\
0.30 \\
0.23 \\
0.19 \\
0.40 \\
0.28 \\
0.23 \\
0.50 \\
0.28 \\
0.33\end{array}$ & $\begin{array}{l}180 \\
260 \\
150 \\
220 \\
160 \\
250 \\
350 \\
280 \\
280 \\
170 \\
275 \\
325 \\
310 \\
200 \\
170 \\
200 \\
220 \\
300 \\
300 \\
200 \\
250 \\
300 \\
250 \\
170 \\
250 \\
300 \\
275 \\
250 \\
350 \\
275 \\
325 \\
320 \\
320 \\
300 \\
275 \\
375 \\
250 \\
250\end{array}$ & $\begin{array}{l}3.90 \\
1.50 \\
4.50 \\
1.85 \\
3.50 \\
1.00 \\
0.50 \\
0.70 \\
0.60 \\
1.80 \\
0.67 \\
0.49 \\
0.50 \\
1.00 \\
1.30 \\
0.85 \\
0.70 \\
0.37 \\
0.35 \\
0.75 \\
0.37 \\
0.25 \\
0.35 \\
0.60 \\
0.25 \\
0.15 \\
0.18 \\
0.20 \\
0.10 \\
0.15 \\
0.10 \\
0.10 \\
0.10 \\
0.10 \\
0.10 \\
0.05 \\
0.10 \\
0.10\end{array}$ & $\begin{array}{l}0.08\left(\times 10^{-4}\right) \\
0.10 \\
0.10 \\
0.11 \\
0.11 \\
0.16 \\
0.16 \\
0.18 \\
0.19 \\
0.19 \\
0.19 \\
0.19 \\
0.21 \\
0.25 \\
0.26 \\
0.29 \\
0.29 \\
0.30 \\
0.31 \\
0.33 \\
0.43 \\
0.44 \\
0.46 \\
0.58 \\
0.64 \\
0.74 \\
0.74 \\
0.80 \\
0.82 \\
0.88 \\
0.94 \\
0.97 \\
0.98 \\
1.11 \\
1.33 \\
1.42 \\
1.60 \\
1.60\end{array}$ \\
\hline $\begin{array}{lc}\text { Mean } & 0.35 \\
\text { S.D. } & \pm 0.098 \\
\text { S.E. mean } & \pm 0.016 \\
\text { t } & 21.9 \\
\text { P }<0.000000001\end{array}$ & $\begin{array}{c}260.1 \\
\pm 57.5 \\
\pm 1.5 \\
173.3 \\
<0.000000001\end{array}$ & $\begin{array}{c}0.78 \\
\pm 1.01 \\
\pm 0.128 \\
6.09 \\
0.00000001\end{array}$ & $\begin{array}{l}0.53 \\
\pm 0.49 \\
\pm 0.079 \\
6.6 \\
<0.00000001\end{array}$ \\
\hline
\end{tabular}

B. CBARACTERISTICB OF TWO OR MORI CURVRES OBTAINRE IN TIVE SUBJECTS

\begin{tabular}{|c|c|c|c|}
\hline 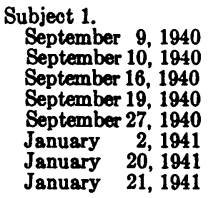 & $\begin{array}{l}300 \\
300 \\
400 \\
300 \\
270 \\
200 \\
220 \\
250\end{array}$ & $\begin{array}{l}0.60 \\
1.00 \\
0.08 \\
0.50 \\
0.35 \\
2.00 \\
1.90 \\
1.40\end{array}$ & $\begin{array}{l}0.18 \\
0.11 \\
0.78 \\
0.22 \\
0.39 \\
0.13 \\
0.19 \\
0.11\end{array}$ \\
\hline $\begin{array}{cr}\text { Subject } 2 . & \\
\text { September 27, } 1940 \\
\text { October } & 4,1940 \\
\text { October } & 11,1940 \\
\text { October } & 23,1940\end{array}$ & $\begin{array}{l}200 \\
200 \\
275 \\
250\end{array}$ & $\begin{array}{l}1.40 \\
0.85 \\
0.10 \\
0.25\end{array}$ & $\begin{array}{l}0.18 \\
0.29 \\
1.32 \\
0.64\end{array}$ \\
\hline $\begin{array}{l}\text { Subject } 3 . \\
\text { September 26, } 1940 \\
\text { Ootober } 1,1940\end{array}$ & $\begin{array}{l}250 \\
225\end{array}$ & $\begin{array}{l}0.25 \\
0.60\end{array}$ & $\begin{array}{l}0.64 \\
0.33\end{array}$ \\
\hline $\begin{array}{l}\text { Subject 4. } \\
\text { September 13, } 1940 \\
\text { October } \quad 7,1940\end{array}$ & $\begin{array}{l}300 \\
250\end{array}$ & $\begin{array}{l}0.20 \\
0.10\end{array}$ & $\begin{array}{l}0.55 \\
1.60\end{array}$ \\
\hline $\begin{array}{l}\text { Subject } 5 . \\
\text { September 20, } 1940 \\
\text { October } 24,1940\end{array}$ & $\begin{array}{l}325 \\
225\end{array}$ & $\begin{array}{l}0.10 \\
0.15\end{array}$ & $\begin{array}{l}0.94 \\
1.32\end{array}$ \\
\hline
\end{tabular}


The meaning of the data shown in Table $I$ is indicated in the statistical treatment shown there. In the bottom line (Table IA), the factors $\mathrm{P}$, calculated according to the recommendation of Mainland (13), has a value of less than $0.000,000,01$. This signifies that, when observations from the same universe of data are obtained by random sampling in a group of similar subjects, a significant difference from the mean here given would occur only once in many thousands of samples. This mean, therefore, should serve as a base-line against which differences in reactivity of the skin vessels attributable to age, sex, disease or other condition may be shown with a high degree of confidence by adequate treatment of the data (13).

In conclusion, mention should be made of the fact that, in the plotting of every curve in Figure 10 , a point is reached (the rheobase) at which the line curves and is parallel to the $X$ axis. This is usual in curves of the strength-duration type (10, 11).

\section{SUM MARY}

A method for measuring the excitability of the smallest blood vessels in human skin is described. Two qualities of the stimulus, intensity (in grams) and duration (in seconds per centimeter), are varied at will. The threshold response consists of the white reaction of the triple response, in the middle of which is just discernible the beginning of the red reaction of the triple response. A typical strength-duration curve is found for each skin, and proof is offered to show that it represents liminal, or threshold responses throughout.

The effect of certain physiological variables upon the threshold response is established: The threshold is raised progressively with circulatory stasis; in systemic anoxemia, the threshold is raised, and in systemic hypercapnea it is lowered. In both cases these changes are well-marked before there is significant alteration in heart rate, systolic or diastolic blood pressure, or in respiratory rate, depth or minute volume. A change in the temperature of the skin, by direct heating, brings about a change in threshold of about 2 per cent per degree Fahrenheit; the threshold responses are read to only 5 or 10 per cent, so that minor changes in room temperature during the course of an experiment do not affect the results seriously.

A procedure is described and applied to a series of data by which a coefficient of excitability is obtained. For the group of normal subjects, this offers a base line for comparison of the effects of experiment, disease or therapeutic procedure upon the sensitivity of the smallest vessels of the skin.

\section{BIGLIOGRAPHY}

1. Krogh, A., Anatomy and physiology of capillaries. Yale University Press, New Haven, 1929.

2. Lewis, T., The blood vessels of the human skin and their responses. Shaw, London, 1927.

3. Moon, V. H., Shock and related capillary phenomena. Oxford University Press, New York, 1938.

4. Collens, W. S., and Wilensky, N. D., Peripheral vascular diseases; diagnosis and treatment. Thomas, Springfield, Ill., 1939.

5. Homans, J., Circulatory diseases of the extremities. Macmillan, New York, 1939.

6. Kramer, D. W., Manual of peripheral vascular disorders. Blakiston, Philadelphia, 1939.

7. Reynolds, S. R. M., and Foster, F. I., Peripheral vascular action of estrogen in the human male. J. Clin. Invest., 1939, 18, 649.

8. Reynolds, S. R. M., Kaminester, S., Schloss, S., and Foster, F. I., Dermovascular action of estrogen in the flush of the surgical menopause. Surg., Gynecol., and Obstet., 1941. (In press.)

9. Arrhenius, S., Quantitative laws in biological chemistry. Bell, London, 1915.

10. Davis, H., and Forbes, A., Chronaxie. Physiol. Rev., 1936, 16, 407.

11. Lapicque, L., L'excitabilité en fonction du temps; la chronaxie, sa signification et sa mesure. Les Presses Universitaires, Paris, 1926.

12. Lassalle, H., Sur une méthode d'évaluation de l'excitabilité neuromusculaire. Discussion théorique. Compt. rend. Soc. de Biol., 1928, 98, 273.

13. Mainland, D., The treatment of clinical and laboratory data. Oliver and Boyd, Edinburgh, 1938. 